\title{
A retrospective analysis of recurrent pediatric ependymoma reveals extremely poor survival ind ineffectiveness of current treatments across central nervous locations and molecular subgroups.
}

Trggve Lundar ${ }^{1}$, Bernt Due-Tønnesen ${ }^{1}$, and Radek Fric ${ }^{1}$

${ }^{1}$ Oslo University Hospital

June 3,2021

A retrospective analysis of recurrent pediatric ependymoma reveals extremely poor survival ind ineffectiveness of current treatments across central nervous locations and molecular subgroups.

Tryggve Lundar MD, $\mathrm{PhD}^{1,2}$, Bernt Johan Due-Tønnessen MD,PhD ${ }^{1}$

Radec Fric MD,PhD ${ }^{1}$

Department of Neurosurgery, Oslo University Hospital ${ }^{1}$ and University of Oslo ${ }^{2}$

Correponding author:

Tryggve Lundar

Department of Neurosurgery

Oslo University Hospital

Postboks 4950 Nydalen, Oslo, Norway

Email: tryggve.lundar@gmail.com

Total word count: 474

Short running title: GTR can improve outcome after relapse of pediatric ependymoma

Key words: Pediatric ependymoma, relapse, repeat surgical resection (GTR)

Number of tables: 0

Number of figures: 0

Letter to the Editor

Pediatr Blood Cancer

Dear Editor,

RE: Ritzmann TA, Rogers HA, Paine SML, Storer LCD, Jacques TS, Chapman RJ, Ellison D, Donson AM, Foreman NK, Grundy RG.

A retrospective analysis of recurrent pediatric ependymoma reveals extremely poor survival ind ineffectiveness of current treatments across central nervous locations and molecular subgroups.

Pediatr Blood Cancer 2020;67:e28426 
https://doi.org/10.1002/pbc.28426

Congratulations to the authors with their detailed analysis of further management and outcome in pediatric patients who experience recurrence within a few years after initial treatment for ependymomas.

Initial treatment for posterior fossa ependymomas (PFE) is maximal surgical resection (Gross total resectionGTR; if possible) followed by local radiotherapy or chemotherapy in small children. For supratentorial ependymomas (STE) GTR is also recommended (if possible) with or without postoperative radiotherapy.

The management at relapses is, however, without consensus. The authors confirm the grave prognosis for these children. In the beginning of the discussion they state: Although primary surgery and irradiation reduced relapse risk variability in different intracranial locations, once a patient recurred these interventions gave, at best, short-term benefits, confirming the need for better therapies.

This of course true - better therapies are urgently needed. They point to the lack of consensus regarding treatment at relapse, but recent guidelines have recommended the use of reirradiation and further surgery. In the conclusion they underline that recurrent pediatric ependymoma is highly aggressive with extremely poor outcome.

This negative statement, is to some extent, in conflict with the results given under 3.5.2. At relapse: GTR at first relapse was associated with sustained improved EFS (25\% vs 0\% 10-year survival).

This statement is in accord with Vinchon et $\mathrm{al}^{1}$ : Total resection is the only curative treatment for RIE (recurrent intracranial ependymoma) and is often possible, especially when the initial resection was total.

How often GTR is within reach at local relapes may be a difficult matter. We have, however, observed several patients who underwent GTR after recurrence, and are tumor-free today after many years of further followup(up to 27 years) without any additional treatment ${ }^{2}$. We recognize that these patients are few compared to the majority of pediatric ependymoma patients who do not grow-up to be well functioning adults. It is, however, important for these small patients and their caretakers to have a hope for cure even after relapse. The role of GTR if possible may be under-communicated.

Kind regards

Tryggve Lundar

Bernt Johan Due-Tønnessen

Radek Fric

Conflict of interest

We confirm that there is no conflict of interest.

References:

Vinchon M, Leblond P, Noudel R, Dhellemmes P. Intracranial ependymomas in childhood: recurrence, reoperation, and oucome. Childs Nerv Syst 2000: 21:221-226.

Lundar T, Due-Tønnessen BJ, Fric R, Brandal P, Due-Tønnessen P. Adult outcome after treatment of pediatric posterior fossa ependymoma: long-term follow-up of a single consecutive institutional series of 22 patients with more than 5 years of survival. J Neurosurg Pediatr. 2020, 26:22-26. 